\title{
O PAPEL DA INTERLEUCINA 10 NA INFECÇÃO PELO PAPILOMAVÍRUS HUMANO DE ALTO RISCO ASSOCIADO A CARCINOGÊNESE CERVICAL.
}

\author{
THE ROLE OF INTERLEUKIN 10 IN HIGH RISK HUMAN \\ PAPILLOMAVIRUS INFECTION ASSOCIATED WITH CERVICAL \\ CARCINOGENESIS.
}

\section{Laíza Alves da Silva (SILVA, L.A.)}

Discente do Curso de Biomedicina. Faculdade Evangélica de Ceres, Ceres-GO,

Brasil.1aizaalves67@gmail.com

\section{Maryane Alves Gomes (GOMES, M.A.)}

Discente do Curso de Biomedicina. Faculdade Evangélica de Ceres, Ceres-GO, Brasil. maryane.alves15@ hotmail.com

\section{Larisse Silva Dalla Libera (LIBERA, L.S.D.)}

Mestre em Ciências da Saúde com ênfase em Patologia Clínica e Doenças Humanas pelo Programa de Pós-graduação em Ciências da Saúde da Universidade Federal de Goiás. Docente da Faculdade Evangélica de Ceres, Ceres -GO, Brasil. larisse.dalla@gmail.com

\section{Endereço para correspondência:}

Av. Brasil, S/n, Qd. 13, Morada Verde. Ceres - GO, Brasil. CEP: 76300-000. Email: maryane.alves15@hotmail.com

\section{RESUMO:}

Introdução: A história natural do câncer cervical está associada a presença persistente da infecção pelo Papilomavírus humano (HPV) de alto risco. Vários fatores imunológicos, estão envolvidos nesse processo, entre eles a IL-10, uma citocina multifuncional que auxilia na progressão tumoral.Objetivo: Descrever o papel da IL-10 na infecção pelo HPV de alto risco em cânceres do colo do útero. Metodologia: Tratou-se de uma revisão integrativa da literatura, em que foram analisadas publicações indexadas na base MEDLINE, consultadas por meio do PubMed; Biblioteca Virtual de Saúde (BVS) e Scientific Eletronic Library Online (SciELO), e buscadores como Google acadêmico. Resultado e Discussão: Sete estudos foram incluídos na revisão, os quais mostraram que níveis mais altos de IL-10 estão presentes em microambientes tumorais com crescimento celular induzido pelo HPV. A prevalência geral do HPV foi de 85,7\%. A principal metodologia de análise da IL-10 foi ELISA, e o tipo histológico tumoral mais encontrado 
foi o carcinoma de células escamosas (CEC). CONCLUSÃO: A IL-10 tem o papel de ajudar na promoção da carcinogênese induzida por HPV de alto risco em cânceres do colo do útero. Estudos que investiguem o papel da IL-10 associada ao HPV são escassos, mas necessários para traçar um caminho mais claro da atuação da IL-10 na resposta imunológica durante o processo carcinogênico.

Palavras-chaves: Carcinogênese. Interleucina 10. Papilomavírus humano.

\section{ABSTRACT:}

Introduction: The natural history of cervical cancer is associated with the persistent presence of high-risk human papillomavirus (HPV) infection. Several immunological factors, are involved in this process, including IL-10, a multifunctional cytokine that helps in tumor progression. Objective: To describe the role of IL-10 in high-risk HPV infection in cervical cancers. Methodology: This is an integrative literature review, in which publications indexed in the MEDLINE database were analyzed, consulted through PubMed; Biblioteca Virtual de Saúde (BVS) and Scientific Eletronic Library Online (SciELO) and search engines like academic Google. Result and Discussion: Seven studies were included in the review; which higher levels of IL-10 are present in tumor microenvironments with HPV- induced cell growth. The overall prevalence of HPV was $85.7 \%$. The main IL-10 analysis methodology for ELISA, and the tumor histological type most found was the squamous cell carcinoma (SCC). Conclusion: IL-10 has the role of helping to promote high-risk HPV-induced carcinogenesis in cervical cancers. Studies investigating the role of IL- 10 associated with HPV are scarce, but available to outline a clearer pathway for IL-10 to act in the immune response during the carcinogenic process.

Keywords: Carcinogenesis. Interleukin 10. Human papillomavirus

\section{INTRODUÇÃO}

O câncer de colo do útero é um tumor comum, no qual a prevalência é de 1.495.211 casos (2018) e causa aproximadamente 341.831 mortes a cada ano, em todo mundo (IARCA, 2021). No Brasil, são estimados 16.710 casos incidentes, sendo que em 2019 o número estimado de mortes foi de aproximadamente 6.596 casos $(6,0 \%)$ em mulheres de todas as idades (INCA, 2021). A sobrevida em cinco anos para este tumor é de 66,3\% (SEER, 2021).

A história natural do câncer cervical já é bem documentada e está associada a presença persistente da infecção pelo Papilomavírus humano (HPV) de alto risco. Este vírus é transmitido predominantemente por contato sexual e pode ser classificado em alto e baixo risco de acordo com sua capacidade de causar lesões malignas. Geralmente a infecção por HPV regride naturalmente, mas o vírus pode infectar o tecido epitelial da cérvice uterina ou tecidos mucosos e cutâneos de outros órgãos, como vulva, vagina, pênis, ânus e orofaringe e causar lesões benignas como papilomas ou mesmo neoplasias pré cancerosas e carcinomas (FORMAN et al., 2012). A inflamação induzida pelo HPV associada ao tumor, envolve teoricamente a estimulação da secreção de moléculas inflamatórias como citocinas, 
quimiocinas, fatores angiogênicos e proteases que promovem o crescimento celular (KOBAYASHI et al., 2008).Vários fatores imunológicos especialmente aqueles relacionados a imunidade inata, que são aprimeira linha de defesa contra infecções, estão envolvidas no reconhecimento e eliminação do HPV (DAUD et al., 2011; SCOTT et al., 2015).

A resposta inflamatória ao tumor, desempenha um papel na tolerância imunológica e suprime as respostas antitumorais, como, a atuação de macrófagos polarizados no microambiente tumoral que contribuem localmente para a imunossupressão, ou mesmo a ação de células dendríticas (DCs) que podem produzir citocinas imunossupressoras, como a interleucina10 (IL-10) e o fator de crescimento de transformação (TGF) (KOBAYASHI et al., 2008).

A IL-10 é uma citocina multifuncional produzida por linfócitos T helper 2 (Th2) que tem a capacidade de inibir o crescimento e a metástase de tumores em vários tipos de cânceres (JAMMAL et al., 2015; LIU et al., 2012). Esta interleucina também pode atuar restringindo fatores angiogênicos, como o fator de crescimento endotelial vascular (VEGF), interleucina 1 beta (IL-1 $\beta$ ), fator de necrose tumoral alfa (TNF- $\alpha$ ), interleucina 6 (IL-6) e metaloproteinases, ou atuar melhorando a lise de células tumorais dependentes de células natural killer (NK) (KUNDU; FULTON, 1997; WANG et al., 2013). A IL-10 está relacionada com a melhora da proliferação e expressão de moléculas de superfície imunologicamente importantes e com o aumento da produção de citocinas por T helper 1 (Th1) e o potencial citotóxico de linfócitos T $\left(\mathrm{CD}^{+}\right)$específico para HPV (SANTIN et al., 2000).

Há indícios na literatura de que níveis mais altos de IL-10 estão presentes em microambientes tumorais com crescimento celular induzido pelo HPV e que contenham células com atividade de replicação viral e ou transformação maligna pelo vírus (MARQUES; CIZZA; STERNBERG, 2007). É importante salientar que a expressão da IL-10 é diretamente proporcional ao desenvolvimento de câncer cervical com detecção de HPV de alto risco, sugerindo uma relação entre IL-10, HPV e o estágio do câncer cervical (BERMUDEZMORALES et al., 2008b). Dessa forma, considerando a associação entre IL-10 e HPV, este trabalho teve por objetivo, descrever o papel da IL-10 na infecção pelo HPV de alto risco em cânceres do colo do útero.

\section{METODOLOGIA}

\section{Tipo de estudo}

Trata-se de uma revisão integrativa da literatura que buscou evidenciar e discutir o 
papel da IL-10 na infecção pelo HPV de alto risco associado a carcinogênese cervical.

\section{Busca e seleção dos estudos}

A busca e coleta dos dados foi baseada nas considerações e protocolos para busca de Souza, Silva e Carvalho, 2010 e (BOTELHO; CUNHA; MACEDO, 2011). Foram consultadas as publicações indexadas na base MEDLINE por meio do PubMed; Biblioteca Virtual de Saúde (BVS) e Scientific Eletronic Library Online (SciELO). Buscadores como o Google acadêmico também foram consultados para inclusão dos artigos.

Foram utilizados os seguintes operadores boleanos e termos de pesquisa em inglês MESH (Medical Subject Headings): "Interleukin-10 OR IL-10 AND Human papillomavirus OR HPV AND Cervical cancer OR Cancer, Uterine Cervical”. E em português pelos termos DECS (Descritores em saúde): "Papilomavírus Humano OR HPV AND Interleucina 10 OR IL-10 AND Câncer cervical OR Câncer do colo do útero".

O processo de localização e seleção dos artigos foi conduzido por dois pesquisadores de forma independente e um terceiro pesquisador finalizou o processo de tomada de decisão.

Não houve delimitação de tempo ou período para os estudos. Uma busca manual na lista de referências dos artigos incluídos com essa estratégia de busca também foi realizada, para garantir a inclusão de todos os artigos relevantes ao tema. As publicações em duplicatas foram removidas manualmente.

\section{Critérios de inclusão e exclusão}

Foram incluídos artigos completos publicados em inglês ou português, que detectaram HPVs de alto risco (de acordo com a classificação da Organização Mundial de Saúde), em carcinomas cervicais e que analisaram a expressão de interleucina 10 nestes tumores.

Foram excluídos trabalhos que não descreveram adequadamente as metodologias de detecção do HPV como genotipagem do vírus ou material utilizado para extração de DNA viral e que avaliaram apenas neoplasias intraepiteliais, também foram excluídos os trabalhos que avaliaram a expressão de interleucina 10 in vitro.

\section{Análise dos dados}

Os dados extraídos dos estudos analisados foram autor, periódico, ano de publicação, região do estudo, tamanho da amostra, metodologia de análise, tipo de material utilizado nas análises, prevalência e genotipagem do HPV e expressão de interleucina 10. Todos os resultados encontrados foram descritos no texto e armazenados no Microsoft Excel, versão 
2013. Os resultados foram organizados e resumidos em forma de tabelas e figuras. A análise da variação de proporção foi realizada utilizando a pontuação de Wilson, pelo programa OpenEpi.

\section{RESULTADOS E DISCUSSÃO}

A dupla função biológica da IL-10 como anti-inflamatória (potencialmente promotora de câncer) e anti-angiogênica (potencialmente supressora de câncer) representa nos tumores cervicais elementos conflitantes (CLERICI et al., 1997; MOTA et al., 1999). E a investigação da interação da IL-10 com o HPV se faz cada vez mais necessária, para elucidar as controversas que existem nas funções biológicas da IL-10, bem como caracterizar as vantagens de uma boa resposta imunológica do hospedeiro na promoção de um câncer (AZAR et al., 2004; BERMUDEZ-MORALES ET AL., 2008; BROWER, 2005).

Sendo assim, inicialmente um total de 500 publicações com essa temática foram levantadas, mas apenas sete estavam de acordo com os critérios de inclusão. A figura 1 apresenta a busca e seleção dos artigos.

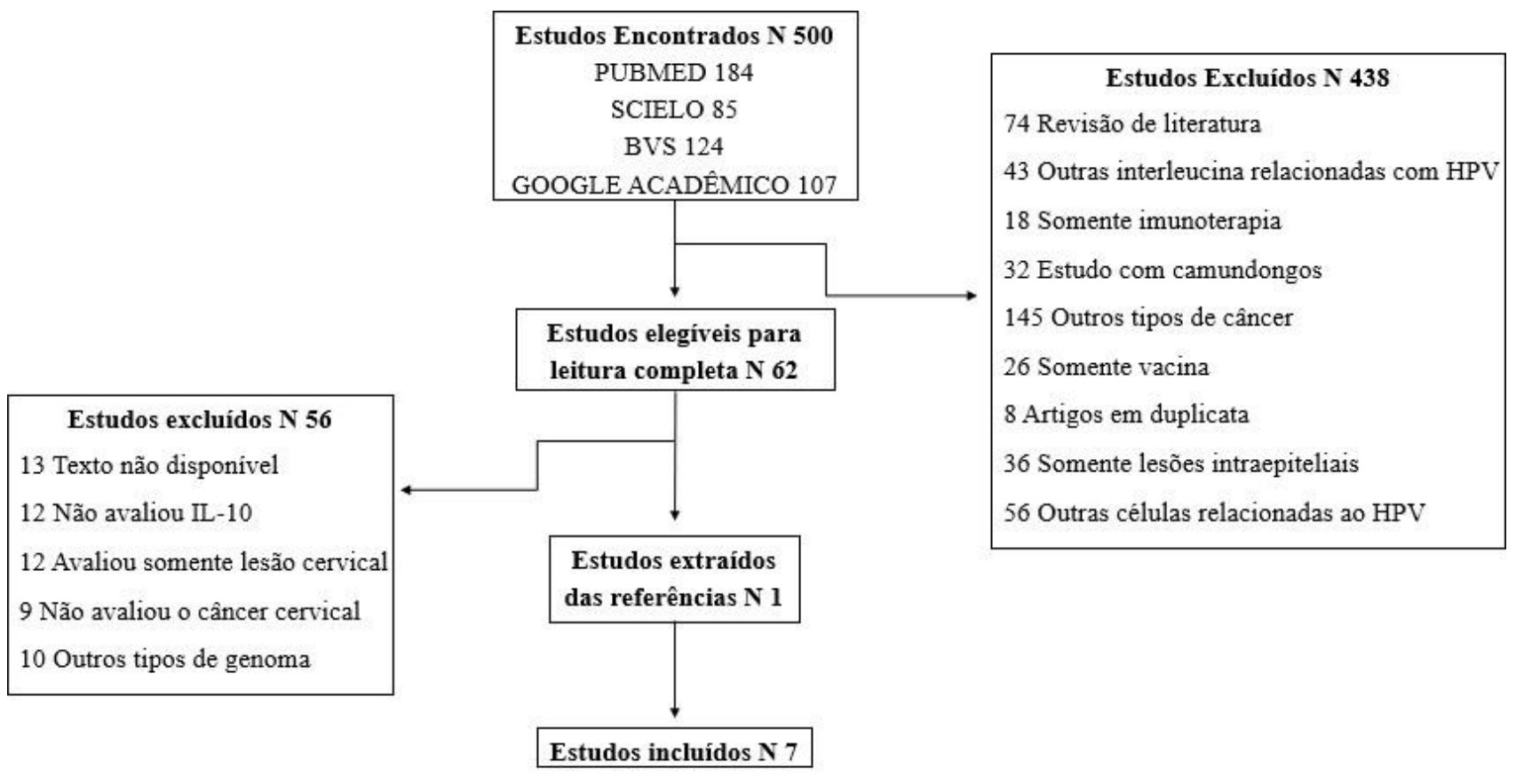

TOTAL $=7$

Figura 1. Busca e seleção dos estudos que avaliaram a presença da IL-10 e do HPV no câncercervical.

A maioria das publicações incluídas, apresentou alta atividade de IL-10 em amostras positivas para o HPV (ALCOCER-GONZÁLEZ et al., 2006a; ALI; ALI; JUBRAEL, 2012; BERMUDEZ-MORALES et al., 2008; BHAIRAVABHOTLA et al., 2007; DU et al., 2019; PRATA et al., 2015; SINGHAL et al., 2015). Mas um dos estudos não encontrou associação 
entre o HPV e a IL-10 sérica (BERMUDEZ-MORALES et al., 2008) (tabela 1 e 2). 
$\underline{\text { Tabela } 1 \text { - Características gerais dos estudos em relação ao desenho e tumor investigado. }}$

\begin{tabular}{cccccc}
\hline Publicação & $\begin{array}{c}\text { Local do } \\
\text { estudo }\end{array}$ & Tipo de estudo & $\begin{array}{c}\text { Casos } \\
\text { (amostra) }\end{array}$ & Idade média & Tipo de tumor \\
\hline DU et al., 2019 & China & Caso controle & 522 & Não descrito & Carcinoma de células escamosas 86.4\% (451); Adenocarcinoma 8.8\% (46); \\
Outros 4,8\% (25) \\
PRATA et al., 2015 & Brasil & Retrospectivo & 84 & 39,2 & Neoplasia e carcinoma; NIC I 25\% (21); NIC II 23,8\% (20); NIC III 19\% (16); \\
Carcinoma 26,1\% (22).
\end{tabular}

Siglas: NIC I - Neoplasia Intraepitelial Cervical Grau I; NIC II - Neoplasia Intraepitelial Cervical Grau II ; NIC III - Neoplasia Intraepitelial Cervical Grau III. 
Tabela 2 - Características gerais dos estudos em relação a metodologia e resultados da IL-10 e o HPV.

\begin{tabular}{|c|c|c|c|c|c|c|}
\hline Publicação & Origem amostra & Análise de HPV & $\begin{array}{c}\text { Análise de } \\
\text { IL-10 }\end{array}$ & $\begin{array}{c}\text { HPV \% } \\
\text { (n) }\end{array}$ & Genótipos HPV & Atividade da IL-10 \\
\hline $\begin{array}{l}\text { DU et al., } \\
2019\end{array}$ & $\begin{array}{l}\text { Caso (522): Soro e } \\
\text { cultura de células } \\
\text { mononucleares de } \\
\text { sangue periférico } \\
\text { (soro); Controle (550): } \\
\text { Mesmas amostras } \\
\text { saudáveis sem infecção } \\
\quad \text { por HPV }\end{array}$ & $\begin{array}{c}\text { PCR; Não } \\
\text { descreveu } \\
\text { metodologia de } \\
\text { genotipagem }\end{array}$ & $\begin{array}{l}\text { PCR, } \\
\text { Sequenciam } \\
\text { ento de } \\
\text { Sanger e } \\
\text { ELISA } \\
\text { (níveis } \\
\text { séricos) }\end{array}$ & $\begin{array}{c}81,4 \% \\
(425 / 522)\end{array}$ & $\begin{array}{l}\text { HPV } 16 \\
(60,1 \%) \\
18(11,4 \%) \\
31(2,5 \%) \\
58(1,7 \%) \\
45(1,7 \%) \\
52(1,7 \%) \\
69(1,4 \%)\end{array}$ & $\begin{array}{l}\text { Foram avaliadas três variantes do promotor da IL-10 (IL 10- } \\
592 \text { C/A; -819 C/T; -1082 A/G). Na avaliação os resultados } \\
\text { mostraram que -592 genótipos AA e CA foram } \\
\text { significativamente associados ao câncer cervical e os } \\
\text { genótipos CC e CT da variante }-819 \text {, foram associados a um } \\
\text { aumento modesto nas chances de desenvolver câncer cervical. } \\
\text { Não houve relação da variante }-1082 \text { com este câncer. }\end{array}$ \\
\hline $\begin{array}{l}\text { PRATA et al., } \\
2015\end{array}$ & Parafinada & $\begin{array}{l}\text { PCR/RFLP e Sybr- } \\
\text { Green }\end{array}$ & IHQ & $\begin{array}{l}90,5 \% \\
(76 / 84)\end{array}$ & $\begin{array}{c}\text { HPV } 16 \\
(48,7 \%) \\
18(43,4 \%) \\
45(13,2 \%) \\
2,33,20 \text { e } 22\end{array}$ & $\begin{array}{l}\text { Resultados indicam a existência de um microambiente } \\
\text { altamente imunossupressor composto por diferentes fenótipos } \\
\text { celulares produtores de IL-10 em amostras de câncer cervical, } \\
\text { e amostras classificadas como lesões cervicais de alto grau. } \\
\text { Foram identificados queratinócitos, macrófagos e CTLs } \\
\text { produtores de IL-10, além de aumento do número de células } \\
\text { Treg e APCs MHC classe II positivas em lesões de alto grau e } \\
\text { câncer cervical. }\end{array}$ \\
\hline $\begin{array}{l}\text { SINGHAL et al., } \\
2014\end{array}$ & $\begin{array}{l}\text { Caso (256): Biopsia, } \\
\text { esfregaço a fresco e } \\
\text { Soro. Controles (250): } \\
\text { Mesmas amostras } \\
\text { saudáveis }\end{array}$ & PCR/ MY09/11 & $\begin{array}{l}\text { PCR/RFLP e } \\
\text { ELISA }\end{array}$ & $\begin{array}{c}89,4 \% \\
(229 / 256)\end{array}$ & $\begin{array}{c}\text { HPV } 16 \\
(94,8 \%) \text { e } 18 \\
(157 \%)\end{array}$ & $\begin{array}{l}\text { Foram avaliadas três variantes do promotor da IL-10 (IL 10- } \\
592 \mathrm{C} / \mathrm{A} ;-819 \mathrm{C} / \mathrm{T} ;-1082 \mathrm{~A} / \mathrm{G}) \text {. Não houve associação do } \\
\text { HPV com o polimorfismo }-819 \text {; mas o genótipo GG do } \\
\text { polimorfismo - } 1082 \text { foi mais frequente em casos infectados } \\
\text { bem como o genótipo CC de }-592 \text {. O haplótipo GTC na } \\
\text { presença de HPV é responsável pela maior expressão de IL- } \\
\text { 10. Na análise da IL-10 em soro, houve um aumento constante } \\
\text { na concentração sérica de IL-10 dos controles }(37,03 \pm 0,4 \\
\text { pg/ml) para lesões pré-câncer }(77,13 \pm 0,35 \text { pg/ml) e câncer } \\
(146,8 \pm 0,4 \text { pg/ml) (p <0,0001), mostrando alto atividade de } \\
\text { IL-10 em tumores cervicais. }\end{array}$ \\
\hline
\end{tabular}

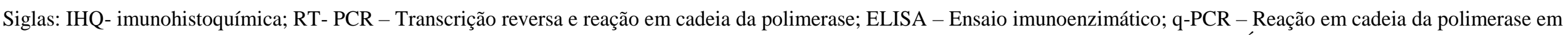

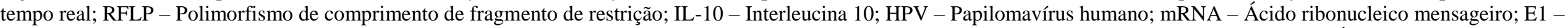

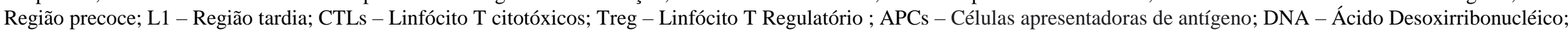
MHC - Complexo Principal de Histocompatibilidade. 
Tabela 2 - Características gerais dos estudos em relação a metodologia e resultados da IL-10 e o HPV (continuação).

\begin{tabular}{|c|c|c|c|c|c|c|}
\hline Publicação & Origem amostra & Análise de HPV & $\begin{array}{c}\text { Análise de } \\
\text { IL-10 }\end{array}$ & $\begin{array}{l}\text { HPV \% \% } \\
\text { (n) }\end{array}$ & Genótipos HPV & Atividade da IL-10 \\
\hline ALI et al., 2012 & $\begin{array}{l}\text { Caso (80): Esfregaço a } \\
\text { fresco e Soro; } \\
\text { Controles (20): } \\
\text { Mesmas amostras } \\
\text { saudáveis }\end{array}$ & $\begin{array}{l}\text { PCR e HPV High } \\
\text { RISK Typing® }\end{array}$ & ELISA & $\begin{array}{c}17,5 \% \\
(14 / 80)\end{array}$ & $\begin{array}{l}\text { Não } \\
\text { diferenciado } \\
\text { (HPV de alto } \\
\text { risco) }\end{array}$ & $\begin{array}{c}\text { Níveis significativamente elevados de IL-10 em amostras } \\
\text { positivas para o HPV em que o nível médio de IL-10 nas } \\
\text { secreções cervicais dos pacientes com HPV positivo foi de } \\
88,73 \%( \pm 16,90) \mathrm{pg} / \mathrm{ml} \text { e } 24 \%( \pm 2,84) \mathrm{pg} / \mathrm{ml} \text { naqueles com } \\
\text { DNA HPV negativo; os níveis dos indivíduos de controle } \\
\text { eram em média } 8,27 \%( \pm 0,59) \mathrm{pg} / \mathrm{ml} \text {. }\end{array}$ \\
\hline $\begin{array}{l}\text { BERMÚDEZ- } \\
\text { MORALES et al., } \\
2008\end{array}$ & $\begin{array}{l}\text { Caso (82): Biopsia, } \\
\text { esfregaço a fresco; } \\
\text { Controle (28): Mesmas } \\
\text { amostras saudáveis }\end{array}$ & $\begin{array}{c}\text { PCR/RFLPs e } \\
\text { primers específicos } \\
\text { para L1 do HPV }\end{array}$ & RT-PCR & $\begin{array}{c}74 \% \\
(81 / 110)\end{array}$ & $\begin{array}{l}\text { HPV } 16(49 \%) \\
18(15 \%), 31 \\
(5 \%), 6(1 \%) \mathrm{e} \\
33(1 \%)\end{array}$ & $\begin{array}{l}\text { Aproximadamente } 51 \% \text { dos pacientes com diferentes graus de } \\
\text { lesão expressam IL-10, mas nenhum dos controles apresentou } \\
\text { essa expressão mesmo embora alguns casos fossem HPV } \\
\text { positivos. A expressão para mRNA de IL-10 de baixo grau foi } \\
\text { de } 37 \% \text {, em lesão de alto grau foi de } 62 \% \text {, e câncer cervical } \\
\text { foi de } 84 \% \text {, com associação direta com o HPV16. Não houve } \\
\text { relação do HPV com a IL-10 sérica. }\end{array}$ \\
\hline $\begin{array}{l}\text { BHAIRAVABHO } \\
\text { TA et al., } 2007\end{array}$ & $\begin{array}{l}\text { Biópsia congelada e } \\
\text { Soro }\end{array}$ & $\begin{array}{l}\text { PCR e primers } \\
\text { específicos para } \\
\text { região E1 do HPV }\end{array}$ & RT-PCR & $\begin{array}{c}88 \% \\
(33 / 36)\end{array}$ & $\begin{array}{c}\text { HPV } 16(86 \%) \mathrm{e} \\
18(13 \%)\end{array}$ & $\begin{array}{l}\text { Foi observada uma correlação entre a presença de HPV em } \\
\text { biópsias de tumor cervical e mRNA para IL-10. A expressão } \\
\text { da IL-10 em tumores cervicais foi de } 86,1 \% \text { ( } 31 \text { casos). Não } \\
\text { houve expressão de IL-10 em lesões. }\end{array}$ \\
\hline $\begin{array}{l}\text { ALCOCER- } \\
\text { GONZÁLEZ et } \\
\text { al., } 2006\end{array}$ & $\begin{array}{l}\text { Controle (29): Biopsia } \\
\text { congelada; Controle } \\
\text { (10): Biopsia de tecido } \\
\text { cervical normal } \\
\quad \text { (autopsia) }\end{array}$ & $\begin{array}{c}\text { PCR/RFLP e } \\
\text { primers específicos } \\
\text { para L1 do HPV }\end{array}$ & $\begin{array}{c}\text { RT-PCR } \\
\text { (mRNA)/ } \\
\text { IHQ }\end{array}$ & $\begin{array}{l}100 \% \\
(29 / 29)\end{array}$ & $\begin{array}{l}\text { HPV } 16 \text { e } 18 \\
\quad(100 \%)\end{array}$ & $\begin{array}{l}\text { Houve uma alta correlação entre a imunocoloração de IL-10 e } \\
\text { o nível de expressão de mRNA de IL-10. Os resultados } \\
\text { indicam que o estado imunossupressor no câncer cervical se } \\
\text { deve principalmente à produção de citocinas anti- } \\
\text { inflamatórias (IL-10) pelos queratinócitos transformados e em } \\
\text { menor grau pela infiltração de células fagocíticas, mas não por } \\
\text { células T. }\end{array}$ \\
\hline
\end{tabular}

Siglas: IHQ- imunohistoquímica; RT- PCR - Transcrição reversa e reação em cadeia da polimerase; ELISA - Ensaio imunoenzimático; q-PCR - Reação em cadeia da polimerase em tempo real; RFLP - Polimorfismo de comprimento de fragmento de restrição; IL-10 - Interleucina 10; HPV - Papilomavírus humano; mRNA - Ácido ribonucleico mensageiro; E1 Região precoce; L1 - Região tardia; CTLs - Linfócito T citotóxicos; Treg - Linfócito T Regulatório ; APCs - Células apresentadoras de antígeno; DNA - Ácido Desoxirribonucléico; MHC - Complexo Principal de Histocompatibilidade. 
Há indícios na literatura de que níveis mais altos de IL-10 estão presentes em microambientes tumorais com crescimento celular induzido pelo HPV, contendo células com atividade de replicação viral e ou transformação maligna pelo vírus (MARQUES; CIZZA; STERNBERG, 2007). Isso porque à atuação das oncoproteínas do HPV, como E2, E6 e E7, induziriam a produção de IL-10, por estímulo nos diferentes tipos de células que secretam essa citocina, ou seja, há modulação do microambiente tumoral pelo HPV (ALCOCERGONZÁLEZ et al., 2006b; SYRJÄNEN et al., 2009).

A IL-10 é um alvo comum para muitos vírus em sua tentativa de subverter o sistema imunológico humano (BERMÚDEZ-MORALES et al., 2011; WANG et al., 2012). Esta citocina ajuda na progressão tumoral, sendo produzida por uma ampla população de células, como células mesenquimais, células reguladoras Th2, alguns subconjuntos de células dendríticas, macrófagos teciduais, além de poder ter sua síntese por meio de linfócitos $\mathrm{T}$, linfócitos B, mastócitos, eosinófilos e queratinócitos em microambientes do tecido infectado com HPV (JAMMAL et al., 2015; LIU et al., 2012).

Assim, a IL-10 está implicada na inflamação (MAPARA; SYKES, 2004;MOCELLIN; MARINCOLA; YOUNG, 2005), apresentando um papel importante na evasão do sistema imune. Acredita-se que a IL10, ao reduzir ou inibir a apresentação do antígeno via regulação negativa da expressão de complexo principal de histocompatibilidade (MHC) de classe II em células apresentadoras de antígeno (APCs), bem como de MHC de classe I em células tumorais (HOLLER et al., 2000) contribui para um ambiente imunossupressor e, assim, facilita o escape do tumor (MANNINO et al., 2015; WOODS et al., 1998). Outras vias de imunossupressão induzidas pela IL-10, incluem participação de macrófagos M2 que contribui diretamente para a progressão do tumor pela liberação de fatores (como fator de crescimento endotelial vascular e metaloproteinases de matriz) e que levam a angiogênese e metástase (ALLAVENA et al., 2008; BOYANO et al., 2000).

Estudos com lesões de baixo e alto grau, apresentaram menos atividade da IL-10 (BERMUDEZ-MORALES et al., 2008a; GIANNINI et al., 1998) em comparação com amostras de câncer cervical (BHAIRAVABHOTA et al., 2007; BERMUDEZ-MORALES et al., 2008a). Os níveis de expressão de IL-10 já foram relatados como significativamente mais altos em neoplasia intraepitelial cervical de alto grau infectadas com HPV 16, quando comparados aos níveis no epitélio cervical normal ou lesões de baixo grau (EL-SHERIF et al., 2001; SYRJÄNEN et al., 2009).

Esse achado favorece a ideia de que a resposta imune local desempenha um papel 
importante na história natural da infecção por HPV do colo do útero. Principalmente, porque a proteína E2 do HPV interage com a sequência de reconhecimento do DNA na região promotora do gene da IL-10, sugerindo um possível mecanismo pelo qual as proteínas do HPV regulam a expressão desse gene durante o desenvolvimento do câncer cervical (BERMUDEZ-MORALES et al., 2008a; BERTI et al., 2017a; GIANNINI et al., 2002; MOORE et al., 2016).

Como a IL-10 sérica não foi associada ao HPV, isso apoia a hipótese de que no câncer cervical existe uma geração de microambientes adversos à resposta imune celular (BERMUDEZ-MORALES et al., 2008b). Um estudo sugeriu que as citocinas são derivadas da secreção celular local, o que explica o fato da IL-10 sérica ter menor associação com o HPV do que a IL-10 cervical, já que a infecção pelo vírus ocorre na membrana basal das células presentes na mucosa do colo do útero (CASTLE et al., 2002). A IL-10 por meio de suas propriedades imunossupressoras, também contribui para a persistência do HPV no estabelecimento de uma lesão intraepitelial escamosa de baixo grau a progressão para carcinoma invasivo. A IL-10, têm estado envolvida na inibição da expressão de moléculas e receptores presentes tanto em células tumorais quanto em células de resposta imune, que fazem o reconhecimento e a eliminação de células com danos (BERMUDEZ-MORALES et al., 2008b; GIANNINI et al., 2002; MOORE et al., 2016).

Em relação as amostras que possuem câncer, os níveis aumentados de IL-10 indicam a ocorrência de imunossupressão local, visto que a IL-10 estaria inibindo a apresentação de antígenos, a função das células T citotóxicas, a proliferação das células T e a secreção de citocinas pró-inflamatórias, o que contribui para a instalação e o desenvolvimento de lesões cervicais após a infecção pelo HPV (GIANNINI et al., 2002).

A IL-10 exerce vários efeitos sobre diferentes populações celulares, incluindo a expansão de células reguladoras $\mathrm{T}$ do Tipo1 $(\operatorname{Tr} 1)$ e um subconjunto de células $\mathrm{T}$ reguladoras que desempenham um papel na inibição da maturação de células dendríticas, isto é, prejudicando a apresentação do antígeno, produção de citocinas e supressão da ativação das células NK e CD8 ${ }^{+}$(BERTI et al., 2017). Por isso, a atividade da IL-10 também foi investigada em relação a presença de variantes polimórficas do seu gene em que dois trabalhos incluídos nesta revisão, investigaram as principais variantes da IL-10 (IL 10-592 C/A; -819 C/T; -1082 A/G) (DU et al., 2019; SINGHAL et al., 2015). No estudo de (SINGHAL et al., 2015), três variantes do promotor da IL-10 (IL 10-592 C/A; -819 C/T; -1082 A/G) foram avaliados e o genótipo GG do polimorfismo -1082 foi mais frequente em casos infectados com HPV bem como o genótipo CC de -592. Já no estudo de (DU et al., 2019) não houve relação da variante 
-1082 com o câncer cervical.

Como o gene da IL-10 é altamente polimórfico, os níveis de IL-10 parecem ser significativamente influenciados por algumas dessas variantes, que deixam o indivíduo mais susceptível a influência do HPV no tecido (FERNANDES et al., 2015; NI et al., 2013). A variante -592 CA/AA do gene da IL-10 é a mais comum e pode aumentar a suscetibilidade ao câncer cervical, pois leva a super expressão de IL-10, que prejudica a produção de citocinas Th1 com ausência de ativação de células T e dificulta a apresentação de antígenos (ALCOCER GONZÁLEZ et al., 2006c; DU et al., 2019). Vale ressaltar, que o polimorfismo na região $592 \mathrm{~A}>\mathrm{C}$ já foi significativamente associado ao risco de câncer de pulmão (CA vs. AA: OR =

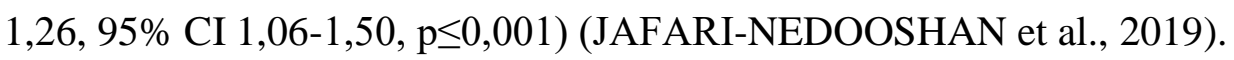

Entre as publicações incluídas a prevalência geral do HPV foi de 79,5\% (887/1117; IC 95\%: 76.9 - 81.7) variando entre 17,5\% (ALI; ALI; JUBRAEL, 2012) e 100\% (ALCOCERGONZÁLEZ et al., 2006b). E os genótipos mais prevalentes foram o HPV 16, 18, 31, 45, 6 e 33 (ALCOCER-GONZÁLEZ et al., 2006a; ALI; ALI; JUBRAEL, 2012; BERMUDEZMORALES et al., 2008b; BHAIRAVABHOTLA et al., 2007; DU et al., 2019; PRATA et al., 2015; SINGHAL et al., 2015).

A infecção persistente pelo HPV de alto risco está associada com o desenvolvimento do câncer cervical (AMORIM CÂNDIDO et al., 2018; OWOSHO et al., 2018). As proteínas virais E6 e E7 estão relacionadas com a carcinogênese mediada pelo HPV, pois são capazes de inativar importantes proteínas supressoras de tumores, como a p53 e a proteína de retinoblastoma $(\mathrm{pRb})$, responsáveis pelo controle do crescimento celular e indução da apoptose (KELLEY et al., 2005). Além disso, os genótipos HPV 16 e 18, são os mais associados a esse processo tumoral (DINIZ, 2010; PRÉTET et al., 2008; ZEFERINO et al., 2018 ).

Entre as metodologias mais empregadas nas avaliações da IL-10, 42,8\% das publicações (ALI; ALI; JUBRAEL, 2012; DU et al., 2019; SINGHAL et al., 2015) avaliaram a IL-10 sérica com o emprego de ELISA. Este teste, se baseia nas ligações antígeno-anticorpo detectáveis através das reações enzimáticas. A utilização da sorologia como possível marcador da infecção pelo HPV, traz imensas dificuldades principalmente em função da sua limitação na genotipagem (RAMA et al., 2006; WESTRA, 2014).

Apenas dois estudos utilizaram a técnica de imunohistoquímica (ALCOCERGONZÁLEZ et al., 2006; PRATA et al., 2015). Esta técnica apresenta um ótimo custo benefício e detecta a expressão de proteínas localizadas nas células dos tecidos, utilizando o 
princípio de ligação entre antígeno e anticorpo (GUO et al., 2008). Com isso, 71,4\% das publicações (ALI; ALI; JUBRAEL, 2012; BERMUDEZ-MORALES et al., 2008; BHAIRAVABHOTLA et al., 2007; DU et al., 2019; SINGHAL et al., 2015) utilizaram outras metodologias, que seriam mais específicas para avaliar a concentração sérica e a relevância funcional do polimorfismo da IL-10. Além disto, a imunohistoquímica pode apresentar algumas limitações, como perda a integridade celular e consequente comprometimento da coloração em decorrência das características de algumas amostras (como amostras parafinadas) (GUO et al., 2008).

O câncer de células escamosas (CEC) foi o tipo histológico de tumor mais analisado dentro dos estudos. O CEC é o tipo histológico de câncer cervical mais associado a infecção persistente por HPV de alto risco (ARQ et al., 2011). A atividade da IL-10 mostrou sua presença aumentada nos casos que apresentaram o tipo histológico carcinoma de células escamosas, e atividade diminuída, mas não insignificante nos outros tumores, mostrando assim que este tipo histológico interfere na atividade da IL-10, por possuir um ambiente imunossupressor propício para a progressão tumoral, que associada a expressão de IL-10, contribui para um prognóstico do paciente.

Em apenas 28,5\% (DU et al., 2019; SINGHAL et al., 2015) dos estudos foram descritos o estadiamento dos tumores, variando entre os estágios I a IV, sendo o mais prevalente os estágios I e II, em que foi observado que a frequência da IL-10 aumentava gradativamente de acordo com a progressão do estadiamento. Nestes estudos, não houve associações significativas entre os estágios clínico patológicos e a expressão de IL-10 do câncer cervical (DU et al., 2019; SINGHAL et al., 2015).

Ao investigar o papel e atividade da IL-10 no prognóstico de diversos tumores além do câncer cervical, como carcinoma de orofaringe, câncer de mama em diferentes populações étnicas e câncer gástrico, percebe-se que apesar da atuação da IL-10 nas vias de resposta imune antitumoral a atividade da IL-10 tende a ser mais imunossupressora, mas ainda não há dados suficientes para considera-la como um possível marcador de prognóstico (ALMEIDA et al., 2019; GARCIA et al., 2013; KOROBEINIKOVA et al., 2015; TIMMANN et al., 2004). Além disso, a infecção por HPV é considerada um fator prognóstico favorável para alguns tipos de cânceres, como os de orofaringe (GILLISON, 2006; MONTENEGRO; VELOSO; CUNHA, 2014; MOSTRAM et al., 2014; PETITO et al., 2017).

Para detecção e genotipagem do HPV a metodologia mais empregada foi a PCR com primers específicos para reconhecer a região L1 do HPV, principalmente para os genótipos do 
HPV de alto risco HPV 16 e HPV 18. E primers para a região L1 e E1 do vírus, além de MM09/11 e kits específicos de genotipagem (MAGALHÃES et al., 2008), Sybr Green e HPV High RISK Typing®. (ALCOCER-GONZÁLEZ et al., 2006; ALI; ALI; JUBRAEL, 2012; BERMUDEZ-MORALES et al., 2008; BHAIRAVABHOTLA et al., 2007; PRATA et al., 2015; SINGHAL et al., 2015).

A maioria dos estudos foi do tipo retrospectivo e analisou principalmente amostras de soro (ALI; ALI; JUBRAEL, 2012; BHAIRAVABHOTLA et al., 2007; DU et al., 2019; SINGHAL et al., 2015), e biopsia de tecido conservadas por congelamento (ALCOCERGONZÁLEZ et al., 2006b; BERMUDEZ-MORALES et al., 2008b; BHAIRAVABHOTLA et al., 2007; SINGHAL et al., 2015).

A fim de investigar a presença da IL-10 cervical, três estudos trabalharam com esfregaço cervical a fresco (ALI; ALI; JUBRAEL, 2012; BERMUDEZ-MORALES et al., 2008b; SINGHAL et al., 2015) e apenas um manuseou amostras parafinadas (PRATA et al., 2015). A análise molecular de ácidos nucleicos tem tradicionalmente exigido DNA genômico obtido a partir de tecidos á fresco ou congelados, pois a amostra se encontra bem preservada quando extraída desse tipo de material (RIVERO et al., 2006; VINCEK et al., 2003). Embora o DNA extraído de amostras frescas ou congeladas seja o ideal para análises moleculares, nem sempre é possível congelar e/ou obter essas amostras a fresco, quando consideradas as limitações da prática clínica (DEVRIES et al., 2005; VINCEK et al., 2003).

A maioria dos estudos incluídos foram realizados no continente asiático (ALI; ALI; JUBRAEL, 2012; BHAIRAVABHOTLA et al., 2007; DU et al., 2019; SINGHAL et al., 2015) e apesar da prevalência do HPV variar em diferentes países (CASTELLSAGUE; MENA; ALEMANY, 2017; CROW, 2012; GERAETS et al., 2012; WIJESOORIYA et al., 2016) e dentro de um mesmo país em diferentes regiões (COLPANI et al., 2016), ainda não há estudos suficientes para avaliar o papel da IL-10 e HPV por distribuição geográfica.

Apesar do que foi discutido este estudo apresenta algumas limitações como a dificuldade na análise dos dados, já que as publicações incluídas são muito heterogêneas, principalmente em relação a metodologia empregada e amostra analisada. Além disso, as técnicas utilizadas para detecção e genotipagem do HPV também apresentaram limitações pela falta de padronização. No entanto os estudos que investigam o papel da IL-10 na infecção e carcinogênese induzida por HPV de alto risco são escassas e revisões como essas se fazem necessárias.

Apesar das atividades imunossupressoras da IL-10 e HPV, ainda é preciso elucidar o 
papel da IL-10, bem como das demais citocinas no microambiente tumoral. É possível que a IL-10 possa suprimir a imunidade das células T, resultando assim em uma infecção persistente por HPV, mas também pode haver um papel direto das células que secretam essa interleucina, como o linfócito T regulador (BASHAW et al., 2020; MINDIOLA et al., 2008).

\section{CONCLUSÃO}

A IL-10 é uma importante citocina anti-inflamatória que por si só promove um estado imunossupressor, mas que parece interagir com as proteínas do HPV, favorecendo ainda mais a imunossupressão do microambiente cervical. As proteínas E2, E6 e E7 do HPV podem exercer influência positiva na transcrição da IL-10, aumentando sua expressão, enquanto a IL-10 promove a expressão do HPV E6 e E7. Como resultado, os níveis cervicais de IL-10 tendem a aumentar e facilitar a progressão da infecção pelo HPV, demonstrando a importante modulação exercida pela IL-10 no desenvolvimento de lesões intraepiteliais a progressão para o câncer cervical.

Mais estudos que investiguem o papel da IL-10 com o HPV ainda são necessários, principalmente os que avaliam o papel dos polimorfismos do gene IL-10 em grupos com tecidos saudáveis, lesões precursoras e câncer positivos e não positivos para a presença do HPV, desta forma é possível traçar um caminho mais claro da atuação da IL-10 na resposta imunológica durante o processo carcinogênico.

\section{REFERÊNCIAS}

ALCOCER-GONZÁLEZ, J. M. et al. In vivo expression of immunosuppressive cytokines in human papillomavirus-transfonned cervical cancer cells. Viral Immunology, v. 19, n. 3, p. 481-491, 2006. Disponível em: 〈https://doi.org/10.1089/vim.2006.19.481> Acesso em: 04 jun. 2020.

ALI, K. S., ALI, H. Y. M., JUBRAEL, J. M. S. Concentration levels of IL-10 and TNF $\alpha$ cytokines in patients with human papilloma virus (HPV) DNA+ and DNA- cervical lesions. Journal of Immunotoxicology, v. 9, n. 2, p. 168-172, 2012. Disponível em: <https://doi.org/10.3109/1547691X.2011.642419> Acesso em: 10 set. 2020.

ALLAVENA, P. et al. Pathways connecting inflammation and cancer. Current Opinion in Genetics and Development, v. 18, n. 1, p. 3-10, 2008. Disponível em: <https://www.sciencedirect.com/science/article/abs/pii/S0959437X08000075> Acesso em: 01 dez. 2020. 
ALMEIDA, V. L. et al. Influence of interleukins on prognosis of patients with oral squamous cells carcinoma. Jornal Brasileiro de Patologia e Medicina Laboratorial, v. 55, n. 5, p. 550-558, 2019. Disponível em: $\leq$ https://doi.org/10.5935/1676-2444.20190051> Acesso em:13 out. 2020.

AMORIM CÂNDIDO, S. et al. Infecção por Papilomavírus Humano de alto risco Oncogênico em mulheres atendidas no Programa de Saúde da Família da Cidade de Serra Talhada, Pernambuco. Medicina Veterinária (UFRPE), v. 11, n. 4, p. 270, 2018. Disponível em: 〈https://doi.org/10.26605/medvet-n4-1956> Acesso em: 13 out. 2020.

ARQ, A. et al. Tracking Precursor Lesions of Anal Squamous Cell. v. 24, n. 2, p. 168-172, 2011. Disponível em: < https://www.scielo.br/pdf/abcd/v24n2/en_a15v24n2.pdf > Acesso em: 20 out. 2020.

AZAR, K. K. et al. Increased secretion patterns of interleukin-10 and tumor necrosis factoralpha in cervical squamous intraepithelial lesions. Human Pathology, v. 35, n. 11, p. 1376-1384, 2004. Disponível em: 〈https://doi.org/10.1016/j.humpath.2004.08.012> Acesso em: 19 out. 2020.

BEN-EZRA, J. et al. Effect of fixation on the amplification of nucleic acids from paraffin embedded material by the polymerase chain reaction. Journal of Histochemistry and Cytochemistry, v. 39, n. 3, p. 351-354, 1991. Disponível em: $\leq$ https://doi.org/10.1177/39.3.1704393> Acesso em: 13 out. 2020.

BERMUDEZ-MORALES, V. H. et al. Correlation between IL-10 gene expression and HPV infection in cervical cancer: a mechanism for immune response escape. Cancer Investigation, v. 26, n. 10, p. 1037-1043, 2008. Disponível em: <https://doi.org/10.1080/07357900802112693>Acesso em:10 set. 2020.

BERMÚDEZ-MORALES, V. H. et al. IL-10 expression is regulated by HPV E2 protein in cervical cancer cells. Molecular Medicine Reports, v. 4, n. 2, p. 369-375, 2011. Disponível em: <https://doi.org/10.3892/mmr.2011.429> Acesso em: 28 out. 2020.

BASHAW, A. A. et al. Regulatory T-cells but not IL-10 impair cell-mediated immunity in HPV+ hyperplastic epithelium. In Journal of Investigative Dermatology. Society for Investigative Dermatology, 2020. Disponível em: 〈https://doi.org/10.1016/j.jid.2020.10.011> Acesso em: 02 dez 2020.

BERTI, F.C.B. et al. The role of interleukin 10 in human papilloma virus infection and progression to cervical carcinoma. Cytokine \& Growth Factor Reviews, v. 34, p. 1-13, 
2017. Disponível em: < https://doi.org/10.1016/j.cytogfr.2017.03.002> Acesso em: 13 out. 2020.

BHAIRAVABHOTLA, R. K. et al. Role of IL-10 in immune suppression in cervical cancer. Indian Journal of Biochemistry and Biophysics, v. 44, n. 5, p. 350-356, 2007. Disponível em:

〈http://nopr.niscair.res.in/bitstream/123456789/135/1/IJBB\%2044\%285\%29\%20\%282007\% 29\%20350-356.pdf> Acesso em: 10 set. 2020.

BOTELHO, L. L. R., CUNHA, C. C. DE A., MACEDO, M. O Método Da Revisão Integrativa Nos Estudos Organizacionais. Gestão e Sociedade, v. 5, n. 11, p. 121, 2011. Disponível em: 〈https://doi.org/10.21171/ges.v5i11.1220> Acesso em: 02 nov. 2020.

BOYANO, M. D. et al. Soluble interleukin-2 receptor, intercellular adhesion molecule-1 and interleukin-10 serum levels in patients with melanoma. British Journal of Cancer, v. 83, n.7, p. 847-852, 2000. Disponível em: <https://doi.org/10.1054/bjoc.2000.1402> Acesso em: 02 dez. 2020.

BROWER, V. Researchers attempting to define role of cytokines in cancer risk. In Journal of the National Cancer Institute, v. 97, n. 16, p. 1175-1177, 2005. Disponível em: 〈https://doi.org/10.1093/jnci/dji269> Acesso em: 10 nov. 2020.

CASTELLSAGUE, X., MENA, M., ALEMANY, L. Epidemiology of HPV-Positive Tumors in Europe and in the World. Recent Results in Cancer Research. Fortschritte Der Krebsforschung. Progres Dans Les Recherches Sur Le Cancer, v. 206, p. 27-35, 2017. 49 Disponível em: <https://doi.org/10.1007/978-3-319-43580-0_2> Acesso em: 13 out. 2020.

CASTLE, P. E. et al. Cervical concentrations of interleukin-10 and interleukin-12 do not correlate with plasma levels. Journal of Clinical Immunology, v. 22, n. 1, p. 23-27, 2002. Disponível em: < https://link.springer.com/article/10.1023/A:1014252402630> Acesso em:02 dez. 2020.

CLERICI, M. et al. Cytokine production patterns in cervical intraepithelial neoplasia: association with human papillomavirus infection. Journal of the National Cancer Institute, v. 89, n. 3, p. 245-250, 1997. Disponível em: 〈https://doi.org/10.1093/jnci/89.3.245> Acesso $11 \mathrm{em}: 05$ nov. 2020.

COLPANI, V. et al. Prevalence of papillomavirus in Brazil: a systematic review protocol. BMJ Open, v. 6, n. 11, 2016. Disponível em: 〈https://doi.org/10.1136/bmjopen-2016011884> Acesso em: 16 out. 2020. 
CROW, J. M. HPV: The global burden. Nature, 2012. Disponível em:

<https://doi.org/10.1038/488S2a> Acesso em: 19 out. 2020.

DAUD, I. I. et al. Association between toll-like receptor expression and human papillomavirus type 16 persistence. International Journal of Cancer, v. 128, n. 4, p. 879886, 2011. Disponível em: 〈https://doi.org/10.1002/ijc.25400〉 Acesso em: 18 abr. 2020.

DEVRIES, S. et al. Array-based comparative genomic hybridization from formalin-fixed, paraffin-embedded breast tumors. Journal of Molecular Diagnostics, v. 7, n. 1, p. 65-71, 2005. Disponível em: 〈https://doi.org/10.1016/S1525-1578(10)60010-4> Acesso em: 19 out. 2020.

DINIZ, G. C. Vírus Do Papiloma Humano (Hpv): Aspectos Moleculares, Reação Imunológica Do Hospedeiro E Bases Do Desenvolvimento Da Vacina. Revista Interdisciplinar de Estudos Experimentais - Animais e Humanos Interdisciplinary Journal of Experimental Studies, v. 1, n. 3, p. 114-120, 2010. Disponível em:

<http://periodicos.ufjf.br/index.php/riee/article/view/23912/13222> Acesso em: 20 nov. 2020.

DU, G. H. et al. Genetic polymorphisms in tumor necrosis factor alpha and interleukin-10 are associated with an increased risk of cervical cancer. International Immunopharmacology, v. 66, n. 32, p. 154-161, 2019. Disponível em:

<https://www.ncbi.nlm.nih.gov/pmc/articles/PMC6348885/> Acesso em: 10 set. 2020.

EL-SHERIF, A. M. et al. Quantitative analysis of IL-10 and IFN- $\gamma$ mRNA levels in normal cervix and human papillomavirus type 16 associated cervical precancer. Journal of Pathology, v. 195, n. 2, p. 179-185, 2001. Disponível em:〈https://doi.org/10.1002/path.929> Acesso em: 02 dez. 2020.

FERNANDES, J. V. et al. Link between chronic inflammation and human papillomavirusinduced carcinogenesis (Review). Oncology Letters, v. 9, n. 3, p. 1015-1026, 2015. Disponível em: <https://doi.org/10.3892/ol.2015.2884> Acesso em: 24 out. 2020.

FERNANDES, J. V. et al. Comparação de três protocolos de extração de DNA a partir de tecido fixado em formol e incluído em parafina. Jornal Brasileiro de Patologia e Medicina Laboratorial, v. 40, n. 3, p. 141-146, 2004. Disponível em: <https://doi.org/10.1590/s167624442004000300003> Acesso em: 15 out. 2020.

FORMAN, D. et al. Global burden of human papillomavirus and related diseases. Vaccine, 30 Suppl 5, p. 12-23, 2012. Disponível em: 〈https://doi.org/10.1016/j.vaccine.2012.07.055> Acesso em: 18 mar. 2020. 
GARCIA, P. et al. Haplotypes of the IL10 gene as potential protection factors in leprosy patients. Clinical and Vaccine Immunology, v. 20, n. 10, p. 1599-1603, 2013. Disponível em: 〈https://doi.org/10.1128/CVI.00334-13> Acesso em: 24 out. 2020.

GERAETS, D. et al. Detection of rare and possibly carcinogenic human papillomavirus genotypes a single infection in invasive cervical cancer. The Journal of Pathology, v. 228, n. 4, p. 534-543, 2012. Disponível em: 〈https://doi.org/10.1002/path.4065> Acesso em: 10 out. 2020.

GIANNINI, S. L. et al. Cytokine expression in squamous intraepithelial lesions of the uterine cervix: Implications for the generation of local immunosuppression. Clinical andExperimental Immunology, v. 113, n. 2, p. 183-189, 1998. Disponível em: <https://doi.org/10.1046/j.1365-2249.1998.00639.x > Acesso em: 30 nov. 2020.

GIANNINI, S. L. et al. Influence of the mucosal epithelium microenvironment on Langerhans cells: Implications for the development of squamous intraepithelial lesions of the cervix.

International Journal of Cancer, v. 97, n. 5, p. 654-659, 2002. Disponível em: <https://doi.org/10.1002/ijc.10084> Acesso em: 16 nov. 2020.

GILBERT, M. T. P. et al. The Isolation of Nucleic Acids from Fixed, Paraffin-Embedded Tissues-Which Methods Are Useful When? PLoS ONE, v. 2 n. 6, 2007. Disponível em: 〈https://doi.org/10.1371/journal.pone.0000537> Acesso em: 11 out. 2020.

GILLISON, M. L. Human papillomavirus and prognosis of oropharyngeal squamous cell carcinoma: Implications for clinical research in head and neck cancers. Journal of Clinical Oncology, v. 24, n. 36, p. 5623-5625, 2006. Disponível em: <https://doi.org/10.1200/JCO.2006.07.1829> Acesso em: 02 dez. 2020.

GUO, M., GONG, Y. et al. Evaluation of a commercialized in situ hybridization assay for detecting human papillomavirus DNA in tissue specimens from patients with cervical intraepithelial neoplasia and cervical carcinoma. Journal of Clinical Microbiology, v. 46, n. 1, p. 274-280, 2008. Disponível em: 〈https://doi.org/10.1128/JCM.01299-07> Acesso em: 17 out. 2020 .

HOLLER, E. et al. Prognostic significance of increased IL-10 production in patients prior to allogeneic bone marrow transplantation. Bone Marrow Transplantation, v. 25, n. 3, p. 237 241, 2000. Disponível em: < https://doi.org/10.1038/sj.bmt.1702126> Acesso em: 02 dez. 2020.

IARCA. Estimated number of deaths in 2018, worldwide, females, all ages. CANCER TODAY, v. 017, p. 1, 2021. Disponível em: $<$ https://gco.iarc.fr/today/online-analysis-multi- 
bars $\mathrm{v}=2020 \&$ mode $=$ cancer $\&$ mode_population $=$ countries \&population $=900 \&$ populations $=90$ $0 \&$ key $=$ total $\&$ sex $=0 \&$ cancer $=39 \&$ type $=0 \&$ statistic $=5 \&$ prevalence $=0 \&$ population group $=0 \&$ ages_group $\% 5 \mathrm{~B} \% 5 \mathrm{D}=0 \&$ ages_group $\% 5 \mathrm{~B} \% 5 \mathrm{D}=17 \& \mathrm{nb}$ items $=10 \&$ group_cancer $=1 \&$ include nmsc $=1 \&$ include nnsc other $=1 \&$ type multiple $=\% 257 \mathrm{~B} \% 2522$ inc $\% 2522 \% 253$ Atrue $\% 252$ C\%2522mort\%2522\%253Afalse\%252C\%2522prev\%2522\%253Atrue\%257D\&orientation=h orizontal\&type_sort=0\&type $n$ nb_items $=\% 257 \mathrm{~B} \% 2522$ top $\% 2522 \% 253 \mathrm{Atrue} \% 252 \mathrm{C} \% 2522 \mathrm{bo}$ ttom\%2522\%253Afalse\%257D > Acesso em: 12 maio 2021.

INCA. INSTITUTO NACIONAL DO CANCER(BRASIL). Disponível em: 〈https://www.inca.gov.br/numeros-de-cancer $>$. Acesso em: 12 maio 2020.

JAFARI-NEDOOSHAN, J. et al. Association of promoter region polymorphisms of IL-10 gene with susceptibility to lung cancer: Systematic review and meta-analysis. Asian Pacific Journal of Cancer Prevention, v. 20, n. 7, p. 1951-1957, 2019. Disponível em: 〈https://doi.org/10.1128/JCM.01299-07> Acesso em: 25 out. 2020.

JAMMAL, M. P. et al. Immunohistochemical staining of tumor necrosis factor- $\alpha$ and interleukin-10 in benign and malignant ovarian neoplasms. Oncology Letters, v. 9, n. 2, p. 979-983, 2015. Disponível em: 〈https://doi.org/10.3892/ol.2014.2781> Acesso em: 16 out. 2020.

KELLEY, M. L., et al. The Global Transcriptional Effects of the Human Papillomavirus E6 Protein in Cervical Carcinoma Cell Lines Are Mediated by the E6AP Ubiquitin Ligase. Journal of Virology, v. 79, n. 6, p. 3737-3747, 2005. Disponível em: <https://doi.org/10.1128/jvi.79.6.3737-3747.2005> Acesso em: 06 nov. 2020.

KOBAYASHI, A. et al. Evolving immunosuppressive microenvironment during human cervical carcinogenesis. Mucosal Immunology, v. 1, n. 5, p. 412-420, 2008. Disponível em: <https://doi.org/10.1038/mi.2008.33> Acesso em: 18 mar. 2020.

KOROBEINIKOVA, E. et al. The prognostic value of IL10 and TNF alpha functional polymorphisms in premenopausal early-stage breast cancer patients. BMC Genetics, v. 16, n. 1, p. 1-11, 2015. Disponível em: <https://link.springer.com/article/10.1186/s12863-015-02348> Acesso em: 05 out. 2020.

KUNDU, N., FULTON, A. M. Interleukin-10 inhibits tumor metastasis, downregulates MHC class I, and enhances NK lysis. Cellular Immunology, v. 180, n. 1, p. 55-61, 1997. Disponível em: 〈https://doi.org/10.1006/cimm.1997.1176> Acesso em: 11 maio 2020.

LIU, C. Z. et al. Overexpression and immunosuppressive functions of transforming growth factor 1, vascular endothelial growth factor and interleukin-10 in epithelial ovarian cancer. Chinese Journal of Cancer Research, v. 24, n. 2, p. 130-137, 2012. Disponível em: 
〈https://doi.org/10.1007/s11670-012-0130-y> Acesso em: 11 nov. 2020.

MAGALHAES, I. M. et al. Comparação de dois pares de oligonucleotídeos utilizados na reação em cadeia da polimerase para detecção de Papilomavírus Humanos em esfregaços cervicais. Jornal Brasileiro de Doenças Sexualmente Transmissíveis, v. 20, n. 2, p. 93-98, 2008. Disponível em: 〈http://www.academia.edu/download/43245243/4.pdf > Acesso em: 06 nov. 2020.

MANNINO, M. H. et al. The paradoxical role of IL-10 in immunity and cancer. Cancer Letters, v. 367, n. 2, p. 103-107, 2015. Disponível em:

<https://doi.org/https://doi.org/10.1016/j.canlet.2015.07.009> Acesso em: 02 dez. 2020.

MAPARA, M. Y., SYKES, M. Tolerance and cancer: mechanisms of tumor evasion and strategies for breaking tolerance. Journal of Clinical Oncology: Official Journal of the American Society of Clinical Oncology, v. 22, n. 6, p. 1136-1151, 2004. Disponível em: 〈https://doi.org/10.1200/JCO.2004.10.041> Acesso em: 25 out. 2020.

MARQUES, A. H., CIZZA, G., STERNBERG, E. Brain-immune interactions and implications in psychiatric disorders. Revista Brasileira de Psiquiatria, v. 29, n. 1, p. 27-32, 2007. Disponível em: 〈https://doi.org/10.1590/S1516-44462007000500006> Acesso em: 18 abr. 2020.

MESQUITA, R. A. et al. Evaluation of 3 methods of DNA extraction from paraffinembedded material for the amplification of genomic DNA using PCR. Pesquisa Odontológica Brasileira = Brazilian Oral Research, v. 15, n. 4, p. 314-319, 2001. Disponível em: <https://doi.org/10.1590/S1517-74912001000400008> Acesso em: 25 out. 2020.

MINDIOLA, R. et al. Increased number of IL-2, IL-2 receptor and IL-10 positive cells in premalignant lesions of the cervix. Investigacion Clinica, v. 49, n. 4, p. 533-545, 2008. Disponível em: < https://www.redalyc.org/pdf/3729/372940297008.pdf> Acesso em: 02 dez. 2020.

MOCELLIN, S., MARINCOLA, F. M., YOUNG, H. A. Interleukin-10 and the immune response against cancer: a counterpoint. Journal of Leukocyte Biology, v. 78, n. 5, p. 1043 46 1051, 2005. Disponível em: 〈https://doi.org/10.1189/jlb.0705358> Acesso em: 16 nov. 2020 .

MONTENEGRO, L. A. S., VELOSO, H. H. P., CUNHA, P. Â. S. M. A. Papilomavírus humano como fator carcinogênico e co-carcinogenico do câncer oral e da orofaringe. Rev Odontol Bras Central, v. 23, n. 67, p. 217-225, 2014. Disponível em: <http://robrac.org.br/seer/index.php/ROBRAC/article/download/834/764> Acesso em: 16 nov. 2020. 
MOORE, K. W. et al. IL-10 acts on the antigen-presenting cell to inhibit cytokine production by Th1 cells. This information is current as Email Alerts Information about subscribing to The Journal of Immunology is online at: on the antigen-presenting cell to inhibit cytokin. v. 146, n. 6, 2016. Disponível em: 〈https://www.jimmunol.org/content/146/10/3444.short> Acesso em: 06 nov. 2020.

MOSTRAM, E., Infec, Q. U. E., Hpv, P., Estar, P., Dos, P., Com, P., \& Orofaringe, N. D. E. Mudança de rumo. p. 22-24, 2014. Disponível em: 〈https://www.inca.gov.br/sites/ufu.sti.inca.local/files//media/document//rrc-31epidemiologia-mudanca-de-rumo.pdf $>$ Acesso em: 13 nov. 2020.

MOTA, F. et al. The antigen-presenting environment in normal and human papillomavirus (HPV)-related premalignant cervical epithelium. Clinical and Experimental Immunology, v. 116, n. 1, p. 33-40, 1999. Disponível em: 〈https://doi.org/10.1046/j.13652249.1999.00826.x > Acesso em: 06 nov.2020.

NI, J., YE, Y., TENG, F., WU, Q. Interleukin 10 polymorphisms and cervical cancer risk: A meta-analysis. International Journal of Gynecological Cancer, v. 23, n. 1, p. 126-133, 2013. Disponível em: 〈https://doi.org/10.1097/IGC.0b013e318274b1a2> Acesso em: 24 out. 2020.

OWOSHO, A. A. et al. Trends in Human Papillomavirus-Related Oropharyngeal Squamous Cell Carcinoma Incidence, Vermont 1999-2013. Journal of Community Health, v. 43, n. 4, p. 731-737, 2018. Disponível em: 〈https://doi.org/10.1007/s10900-018-0477-1> Acesso em: 15 nov. 2020.

PETITO, G. et al. Papilomavírus humano (HPV) em carcinomas de cavidade oral e orofaringe na região central do Brasil. Brazilian Journal of Otorhinolaryngology, v. 83, n. 1, p. 38-44, 2017. Disponível em: 〈https://doi.org/10.1016/j.bjorl.2016.01.004> Acesso em: 16 out. 2020.

PINION, S. B. et al. Oncogene expression in cervical intraepithelial neoplasia and invasive cancer of cervix. The Lancet, v. 337, n. 8745, p. 819-820, 1991. Disponível em: 〈https://doi.org/10.1016/0140-6736(91)92518-7> Acesso em: 28 out. 2020.

PRATA, T. T. et al. Local immunosuppression induced by high viral load of human papillomavirus: Characterization of cellular phenotypes producing interleukin-10 in cervical neoplastic lesions. Immunology, v. 146, n. 1, p. 113-121, 2015. Disponível:

〈https://doi.org/10.1111/imm.12487> Acesso em: 10 set. 2020.

RAMA, C. H., et al. Serological detection of anti HPV 16/18 and its association with pap 
smear in adolescents and young women. Revista Da Associacao Medica Brasileira, v. 52, n. 1, p. 43-47, 2006. Disponível em: 〈https://doi.org/10.1590/s0104-42302006000100021> Acesso em: 28 out. 2020.

RIVERO, E. R. C. et al. Simple salting-out method for DNA extraction from formalin-fixed, paraffin-embedded tissues. Pathology Research and Practice, v. 202, n. 7, p. 523-529, 2006. Disponível em: <https://doi.org/10.1016/j.prp.2006.02.007> Acesso em: 27 nov. 2020.

SANTIN, A. D. et al. Interleukin-10 increases Th1 cytokine production and cytotoxic potential in human papillomavirus-specific CD8+ cytotoxic T lymphocytes. Journal of Virology, v. 74, n. 10, p. 4729-4737, 2000. Disponível em: <https://doi.org/10.1128/JVI.74.10.47294737.2000> Acesso em: 11 maio 2020.

SANTOS, M. de O. Estimativa 2018: Incidência de Câncer no Brasil. Revista Brasileira de Cancerologia, v. 64, n. 1, p. 119-120, 2018. Disponível em: <https://doi.org/10.32635/21769745.rbc.2018v64n1.115> Acesso em: 12 out. 2020.

SANTOS, S. et al. An efficient protocol for genomic DNA extraction from formalin-fixed paraffin-embedded tissues. Research in Veterinary Science, v. 86, n. 3, 421-426, 2009. Disponível em: <https://doi.org/10.1016/j.rvsc.2008.08.007> Acesso em: 24 nov. 2020.

SCORSATO, A. P., TELLES, J. E. Q. Factors that affect the quality of DNA extracted from biological samples stored in paraffin blocks. Jornal Brasileiro de Patologia e Medicina Laboratorial, v. 47, n. 5, p. 541-548, 2011. Disponível em: <https://doi.org/10.1590/s167624442011000500008> Acesso em:26 out.2020.

SCOTT, M. E., Ma, Y., Farhat, S., Moscicki, A. B. Expression of nucleic acid-sensing Tolllike receptors predicts HPV16 clearance associated with an E6-directed cell-mediated response. International Journal of Cancer, v. 136, n. 10, p. 2402-2408, 2015. Disponível em: 〈https://doi.org/10.1002/ijc.29283> Acesso em: 18 abr. 2020.

SEER. NATIONAL CANCER INSTITUTE; SURVEILLANCE,Epimedemiology and Results Program U.seer. Cancer Stat Facts: Cervical Cancer, p. 8, 2021. Disponível em: $\leq$ https://seer.cancer.gov/statfacts/html/cervix.html> Acesso em: 12 maio 2021.

SHRESTHA, S., et al. Interleukin-10 gene (IL10) polymorphisms and human papillomavirus clearance among immunosuppressed adolescents. Cancer Epidemiology Biomarkers and Prevention, v. 16, n. 8, p. 1626-1632, 2007. Disponível em: 〈https://doi.org/10.1158/1055-9965.EPI06-0881> Acesso em: 10 set. 2020.

SINGHAL, P. et al. Association of IL-10 GTC haplotype with serum level and HPV infection 
in the development of cervical carcinoma. Tumor Biology, v. 36, n. 4, p. 2287-2298, 2015. Disponível em: 〈https://doi.org/10.1007/s13277-014-2836-6> Acesso em: 10 set. 2020.

SYRJÄNEN, S. et al. Immunosuppressive cytokine Interleukin-10 (IL-10) is up-regulated in high-grade CIN but not associated with high-risk human papillomavirus (HPV) at baseline, outcomes of HR-HPV infections or incident CIN in the LAMS cohort. Virchows Archiv, v. 455, n. 6, p. 505-515, 2009. Disponível em: 〈https://doi.org/10.1007/s00428-009-0850-7> Acesso em: 16 nov. 2020. 14

THE GLOBAL CANCER OBSERVATORY (IARCA). Estimated number of prevalent cases (5-year) in 2018, worldwide, females, all ages. Cancer Today, v. 476, 2018. Disponível em: <http://gco.iarc.fr/today/online-

analysistable $? \mathrm{v}=2018 \&$ mode $=$ population $\&$ mode $\_$population $=$countries $\&$ population $=900 \& p 0$ pulation

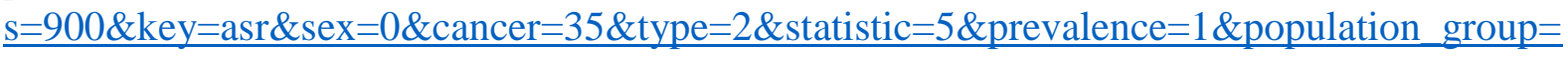
0\&ages_group $\% 5 \mathrm{~B} \% 5 \mathrm{D}=0 \&$ ages_group $\% 5 \mathrm{~B} \% 5 \mathrm{D}=17 \& \mathrm{nb} \_\mathrm{items}=5 \&$ gro $>$ Acesso em: 12 maio. 2021.

TIMMANN, C. et al. Promoter haplotypes of the interleukin-10 gene influence proliferation of peripheral blood cells in response to helminth antigen. Genes and Immunity, v. 5, n. 4, p. 256-260, 2004. Disponível em: <https://doi.org/10.1038/sj.gene.6364094> Acesso em: 07 nov. 2020.

VAN DAM, P. A. et al. RANK-RANKL signaling in cancer of the uterine cervix: A review. International Journal of Molecular Sciences, v. 20, n. 9, p. 1-15, 2019. Disponível em: 〈https://doi.org/10.3390/ijms20092183> Acesso em: 02 dez. 2020.

VIEIRA, P. et al. Isolation and expression of human cytokine synthesis inhibitory factor cDNA clones: Homology to Epstein-Barr virus open reading frame BCRFI. Proceedings of the National Academy of Sciences of the United States of America, v. 88, n. 4, p. 11721176, 1991. Disponível em: 〈https://doi.org/10.1073/pnas.88.4.1172> Acesso em: 27 out.2020.

VINCEK, V. et al. A Tissue Fixative that Protects Macromolecules (DNA, RNA, and Protein) and Histomorphology in Clinical Samples. Laboratory Investigation, v. 83, n. 10, p. 14271435. Disponível em: 〈https://doi.org/10.1097/01.LAB.0000090154.55436.D1〉 Acesso em: 25 nov. 2020.

WANG, L. X., et al. IL-10 Contributes to the Suppressive Function of Tumour-Associated Myeloid Cells and Enhances Myeloid Cell Accumulation in Tumours. Scandinavian Journal of Immunology, v. 75, n. 3, p. 273-281, 2012. Disponível em: $\leq$ https://doi.org/10.1111/j.13653083.2011.02662.x> Acesso em: 25 nov. 2020. 
WANG, Y. et al. The paradox of IL-10-mediated modulation in cervical cancer. Biomedical Reports, v. 1, n. 3, p. 347-351, 2013. Disponível em: 〈https://doi.org/10.3892/br.2013.69> Acesso em: 29 abr. 2020.

WESTRA, W. H. Detection of human papillomavirus (HPV) in clinical samples: Evolving methods and strategies for the accurate determination of HPV status of head and neck carcinomas. Oral Oncology, v. 50, n. 9, p. 771-779, 2014. Disponível em:

〈https://doi.org/10.1016/j.oraloncology.2014.05.004> Acesso em: 28 out. 2020.

WIJESOORIYA, N. S. et al. Global burden of maternal and congenital syphilis in 2008 and 2012: a health systems modelling study. Lancet Global Health, v. 4, n. 8, p. 525-533, 2016. Disponível em: <https://doi.org/10.1016/S2214-109X(16)30135-8> Acesso em: 06 nov. 2020.

WOODS, K. V. et al. Interleukin-1 regulates interleukin-6 secretion in human oral squamous cell carcinoma in vitro: Possible influence of p53 but not human papillomavirus E6/E7.

Cancer Research, v. 58, n. 14, p. 3142-3149, 1998. Disponível em:

〈https://cancerres.aacrjournals.org/content/canres/58/14/3142.full.pdf $>$ Acesso em: $01 \mathrm{dez}$. 2020. 